\title{
From Anecdotal Exchange to Critical Dialogue in Kindergarten: A Case Study in Italy Based on Habermas' Construct of Rational Behavior
}

\author{
Francesca Granone ${ }^{1}$, Francesca Morselli² ${ }^{2}$ Elisabetta Robotti ${ }^{2}$ \\ ${ }^{1}$ Department of Early Childhood Education, University of Stavanger, Stavanger, Norway \\ ${ }^{2}$ Department of Mathematics, University of Genova, Genova, Italy \\ Email: francesca.granone@uis.no
}

How to cite this paper: Granone, F. Morselli, F., \& Robotti, E. (2021). From Anecdotal Exchange to Critical Dialogue in Kindergarten: A Case Study in Italy Based on Habermas' Construct of Rational Behavior. Creative Education, 12, 705-717. https://doi.org/10.4236/ce.2021.124049

Received: February 24, 2021

Accepted: April 5, 2021

Published: April 8, 2021

Copyright $\odot 2021$ by author(s) and Scientific Research Publishing Inc. This work is licensed under the Creative Commons Attribution International License (CC BY 4.0).

http://creativecommons.org/licenses/by/4.0/

\begin{abstract}
The objective of this study was to investigate preschool-aged children's rational behavior and dialogical critical thinking and analyze different types of dialogical exchange about mathematics among 5-years-old children. Based on a two-part theoretical framework, one referred to Habermas' construct of rational behavior and the second to Daniel's model about typology of dialogical exchange among peers, the study shows that a dialogue containing all three components of the rational behavior can be reached by children just when the dialogue is a critical dialogical type. This happens when children show spontaneous and complete justifications, with a critic approach and this allows children to reach a modification of the initial idea as a common solution. Considerations about teacher's role are presented.
\end{abstract}

\section{Keywords}

Kindergarten, Rational Behavior, Dialogical Critical Thinking, Mathematics, Italy

\section{Introduction}

The case reported in this article is part of a collaborative project, funded by mobility funds granted by Division of Research and Innovation (project IN-11881), between Norway and Italy, aimed at investigating how the cultural scenario can enhance the teaching-learning process in preschool, with focus on mathematics, outdoors, rational behavior and dialogical critical thinking. In previous works (Robotti et al., 2020), the authors addressed the possible link between outdoor education and mathematics education. The present study is specifically focused 
on children's rational behavior and dialogical critical thinking during the development of mathematical activities.

Argumentation is considered particularly relevant to the mathematical learning process through social interaction and numerous examples in literature have shown expression of arguments in elementary and secondary classrooms (Krummheuer, 1995). In addition, literature has shown the possibility of identifying argumentation during classroom discussions (Boero, 2011) and different aspects of rationality with respect to argumentation (Boero \& Planas, 2014). The specific of the present study is the fact of addressing pre-school children.

The study was conducted in an Italian kindergarten specifically interested in critical thinking, in order to observe if preschool children's rational behavior and dialogical critical thinking can be identified in children's dialogues and enhanced by teacher's approach. The context was chosen because of the importance that Italy gives to critical thinking, reasoning and argumentation. Since the cultural dimension and the corresponding educational context of a country can be easily deduced from the National Framework, it is important to refer to the "National Guidelines for the curriculum of kindergarten and first cycle of education", issued by the MIUR and in force since 2012 (Ministero della pubblica istruzione, 2012). In this plan it is possible to highlight keywords such as argumentation and reasoning, that show that rational behavior and dialogical critical thinking are considered important already in the early years. For instance: "The child plays constructively and creatively with others, knows how to argue, confront, support his reasons with adults and children" (Ministero della pubblica istruzione, 2012).

Although Italy underlines the importance of critical thinking, mathematics and the role of teachers in supporting children's learning, a specific study with focus related to argumentation at preschool level is lacking. For this reason, the center of the present research is to observe how argumentation cab enhances in Early Childhood Education and Care (ECEC) institutions. In particular, the aim of this study is to analyze dialogical exchanges in ECEC institutions, identifying how children's rational behavior and dialogical critical thinking can be highlighted using a theoretical framework based on Habermas' construct of rational behavior and Daniel's model about typology of dialogical exchange among peers.

\section{Theoretical Framework}

Critical thinking has been described as an essential tool of inquiry and a powerful resource in one's personal and civic life (Golding, 2011). A critical thinker can be someone who has the characteristics of, for example, being inquisitive, open-minded, flexible and trustable, prudent in making judgment and facing biases, focused in inquiry. Educating the child to be a critical thinker should be one of the core objectives of education in ECEC institutions (Siraj, Kingston, \& Melhuish, 2015). To use critical thinking means that a person shows a judicious skepticism, and, as a consequence, it means that the person doesn't take 
a statement as granted, but, instead, considers alternative hypotheses and possibilities (Jenkins \& Cutchens, 2011). This is a key to avoid established rules, and, indeed, having a critical thinking helps to experiment new possibilities and non-conventional approaches. To learn using critical thinking means to learn when to question something, and what type of questions to ask. Critical thinking can be defined as "dialogical" when it is situated in the context of dialogue among peers (Daniel \& Gagnon, 2011). When children argue, a level of mutual agreement can be reached (Daniel \& Fiema, 2017). The acceptance of the best argument for example can happen when the discussion has exhausted all the elements considered important by all of the participant, and the proposed argument is acceptable for everyone. This can happen when the three aspects of rationality are present (Morselli \& Boero, 2009; Levenson \& Morselli, 2018). A connection between critical thinking, rationality and mathematics has been identified (Levenson \& Morselli, 2018).

Mathematics teaching and learning should focus not only on the final product, or the activities in the form "question-answer", but on the process. From the double attention to the process and product characteristics derives a particular care for the control and communication aspects, which finds full resonance in the construct of rational behavior, taken up by the philosopher Habermas (Habermas, 2014) and adapted to the case of mathematics (Levenson \& Morselli, 2018). Habermas' theory has been chosen as the first part of the theoretical frameworks. Habermas describes three components of rational behavior:

- epistemic rationality, that means that an opinion is rational when it is possible to motivate it in a given context;

- teleological rationality, that means that one acts rationally when one acts on the basis of a purpose and pursues the purpose with means intentionally chosen and implemented;

- communicative rationality, that means that one communicates rationally when one consciously chooses the means to make communication effective.

According to Habermas, a subject is capable, in communicating with himself and with others, to justify his actions by relating them to the goal to be achieved (Boero, Douek, Morselli, \& Pedemonte, 2010).

The present study is grounded on an integrated use of Habermas' theoretical construct with the theoretical framework based on Daniel's classification of type of dialogue (Daniel \& Fiema, 2017). This choice has the aim of analyzing the processes of dialogue among peers in terms of rationality.

Daniel highlights that dialogue is not a spontaneous mode of exchange, but it necessitates systematic and regular learning, by means of a praxis. Daniel classifies exchanges in different types:

- Anecdotal: children speak without a structure about personal situations, and they do not have a common goal. They do not justify their point of view, and they are not influenced by peer interventions.

- Monological: children begin to enter a process of inquiry, but they are inter- 
ested in finding "the" correct answer. Children speak independently from one another and have difficult to justify their opinions.

- Dialogical: children begin to form a community of inquiry, and this means that they have a common goal, they construct their interventions based on those of their peers and they try to justify their opinions. When an exchange is dialogical, three types of dialogue can be further distinguished:

o non-critical dialogical: children listen to different opinions, construct their point of view based on those of their peers, and begin to justify their remarks.

o semi-critical dialogical: children are sufficiently critical to question peer statements.

o critical dialogical: children consider different opinions as an enrichment of the community. Peer criticism is considered important and a necessary tool to move forward in comprehension for reaching the common goal.

Within the framework of this study, it is important to include the teacher's role. This relates to the fact that the aim of the study is to understand not just which type of dialogical exchange children can reach, but also how the teacher can enhance this type of dialogue (Daniel \& Fiema, 2017). Research shows that teacher's approach can enhance rational behavior (Conner, 2017) and that mathematics can be a useful starting point for discussing rationally (Zhuang \& Conner, 2018). This because mathematical thinking is linked to the rigor of the proof, to the argumentation of one's own reasons, to the process of constructing and redefining one's reasoning for this mathematical experiences inserted in contexts of everyday life (Quintana \& Correnti, 2019). This is in accordance with literature (Daniel \& Gagnon, 2011; Hundeland, Carlsen, \& Erfjord, 2020). The fact that teacher's role can enhance children's argumentation and rational behavior development is also known (Conner, 2017).

The questions that oriented our research were: Which type of dialogical exchanges among preschool children can be recognized and enhanced? Are the three components of rational behavior identifiable in dialogues among peers? What can we say about teacher's role?

Two types of analyses, stemming from our two-part theoretical framework, were used to answer these questions, for analyzing both children's interventions and rational behavior and teacher's role.

\section{Context}

The study involved twelve 5-years-old Italian children, five boys and seven girls.

Children attending the kindergarten were coming from an average socio economic background. The teacher was chosen because of her knowledge about rational behavior and dialogical critical thinking, developed during the participation to the action research group called Laboratorio Zero (LZ). This group is made up of about ten teachers from ECEC institutions in Liguria (an Italian region), working in partnership with Genova Municipality, inspired to the work of Anna Bondioli (Bondioli, 1996). The aim of this group is to encourage discus- 
sion and training of the teachers involved, emphasizing the importance of some didactic aspects: the child-adult relationship, the teacher as a director, the child discovering his or her autonomy with respect to his/her learning, the importance of reflection and dialogue to develop mathematical thinking, the child who learns to learn. The approach chosen and implemented by teachers of LZ has many points in common with the approach of Philosophy for children (P4C) (Lipman, 2003). In fact, the approach developed with LZ aims to produce some kind of settlement or judgement, is dialogical and involves reasonableness and creativity, in accordance with features that Lipman uses to describe P4C.

\section{Methodology}

The present research project is exploratory. It consists of a case study developed in an ECEC institution in Genova, from February to April 2019.

In meetings organized each week during the research period, teachers involved in this group and researchers have developed insights into how to support children's critical thinking and rational behavior, reinforcing concepts that were grounded in the approach LZ.

The sessions among teacher and children in the ECEC institution took place twice a week, between the third week of February 2019 and the last week of April 2019. The duration of the sessions varied, considering children's level of concentration. During each session the researcher was sitting in a corner, video-recording the activities without participating. The average duration was 20 minutes. All the video recordings were transcribed and checked by a researcher together with the teacher participating in the research.

Each activity was built in the same sequence: the teacher asks a question, a child answer and the teacher tries to enhance the dialogue between peers. All the activities were related to mathematics, connected to topics that was interesting for children (usually a game situation or special occasions such a birthday), used by the teacher as a stimulus for starting a conversation.

Each session was video-recorded and transcribed in full. Written parental consent was provided. Transcripts were anonymised, and children's names were changed to ensure anonymity. Data were kept in a closed space at University of Genova only accessible to the researchers.

For our analysis, we used transcripts of dialogical exchanges. In this article we report results obtained from the analysis, reporting just small part of all the transcriptions, specifically chosen because they significantly reflected the children's types of dialogical exchange. We chose four dialogic exchanges, two in the beginning of the observations (February 2019) and two at the end of the observations (and of April 2019).

This qualitative analysis of children's dialogical exchanges was based on the theoretical framework related to Habermas' construct of rational behavior and Daniel's model about typology of dialogical exchange among peers. Different results are showed, related to different timing. 
The analysis was conducted based on two aspects of the theoretical framework: the typology of types of exchanges by Daniel and colleagues (to analyze the children's interventions) and Habermas' criteria (to analyze both children's rational behavior and teacher's interventions).

\section{Results and Discussion}

In the following sections, we present the qualitative analysis of extracts from the transcripts chosen for the study.

\subsection{Non-Critical Dialogical Type of Exchange, February}

As described before, the teacher introduces a question in a game situation. In this case, the activity is related to a game called "The game of chairs". The teacher doesn't want to explain the activity, but instead use this situation to ask an explanation to children.

Teacher. let's play a game: "The game of chairs". Do all of you know this game?

Matteo: Yes!

Teacher. can you explain it to everyone?

Matteo: put for example 4 chairs and 5 children. The teacher plays the tambourine. The children run around the chairs. When the teacher stops playing, the children sit down. Who stays out, loses.

Teacher. so, what happens? What does the teacher do?

Matteo: She takes away a chair and restarts the game.

Teacher. What did Matteo say? What does the teacher do?

Laura: He said that the teacher takes away a chair.

Teacher. Who of you can explain why?

Matteo: Because...

Teacher. I would like to listen to Sergio. Sergio you didn't say anything, what do you think?

Sergio: ...

Teacher. it doesn't matter if you make hypotheses that are wrong, the important thing is that you make hypotheses because this is how we learn.

Sergio: Because compared to the chairs you need an extra child!

Teacher, have you seen? Good boy!

Sara: Sergio is right, because otherwise children and chairs are even.

Teacher. What do you mean "they are even?"

Sergio: She means that for every child there is a chair.

Elena: If they are even, the game does not work.

Children involved in observations were working, already from September, with a teacher trained to support dialogical critical thinking through the LZ training. The teacher in fact was used to asks open questions, challenging children to find new answers. This had consequently the result that children showed already from the beginning of the research study a propensity for dialogue and 
discussion, as outlined in this first excerpt.

The discussion starts when the teachers ask to explain the game of the chairs. Matteo provides an explanation in terms of description of the rules of the game, afterwards the teacher encourages the children, Sergio in particular, to justify the game structure, namely explaining why the teacher needs to take away one chair. The first thing that can be observed is that teacher asks questions that enhance the discussion about a topic ("What did Matteo say? What does the teacher $d o$ ?") but not yet a critical approach (as asking for example "Does anyone agree with Matteo?"). The epistemic component of rationality (Habermas, 2014) is not enhanced by the teacher, and the other children take the assertion of Matteo as done. Children don't ask for a motivation or an explanation. This can be seen also when Sergio explains the game's rule in a way that is not totally clear ("Because compared to chairs you need an extra child!"). Sara gives an additional explanation that is not completely clear either ("Sergio is right, because otherwise children and chairs are even"). Then Elena tries to summarize, but the rules are not really explained, and the discussion ends. The communicative rationality is not enhanced from the teacher, who never asks children to explain their thought in a better way. We may see some instance of teleological rationality, that could have been promoted ad further developed, since the children answer in reference to the fact of being able to play the game ("otherwise children and chairs are even"; "If they are even, the game does not work").

If we refer to the part of the theoretical framework related to Daniel, we can observe that the teacher poses a question that helps children to set a common goal, and links between pupils can be identified ("She means that for every child there is a chair."). So, children explain their point of view related to the topic; they have interactions that in principle are related among them, but always expressed in a dialogue with the teacher. Moreover, it is possible to underline that the initial idea is improved, but not modified. This implies that a dialogical critical type of exchange is not reached (Daniel \& Fiema, 2017).

Overall, the dialogical exchange analysed is Non-critical, and we can affirm that the three dimensions of Habermas' construct of rational behaviour are not yet fully in action.

\subsection{Semi-Critical Dialogical Type of Exchange February}

In this activity the teacher uses the children's interest in knowing what day of the week is, as a starting point.

Teacher. What day is today?

Matteo: Teacher, today is the $6^{\text {th }}$ ?

Laura: No! the 6 th we were at home!

Teacher. How do you know that?

Laura: The calendar.

Matteo: ... (the child reacts by frowning in an exaggerated way, to show that he does not understand)

Teacher. can you Laura explain what do you mean so that everyone can un- 
derstand?

Laura: The calendar on the wall. It says that the last day that we were here (in the kindergarten) was 5. After, we were two days at home. After, is today. So 6 th we were at home. Today is the $7^{\text {th }}$.

Matteo: This is for school, not for kindergarten

Paolo: It's not true! We were at home two days!

Laura: So today is the $7^{\text {th }}$.

Paolo: two days! So it is ... so it is ...

Laura: the $7^{\text {th }}$.

Paolo: the $8^{\text {th }}$ !

Laura: No no no! It is the $7^{\text {th }}$ !

Teacher. Matteo: Can we ask to someone else if he/she can try another explanation?

(no one answer and the conversation is ended).

In this situation children show that they are interested in discussion, and that they listen and evaluate other opinions. However, the children do not accept to change their opinion. Although dialogue shows an exchange that can be defined as dialogic, it does not reach the critical-dialogic level but stops at that of semi-critical (Daniel \& Fiema, 2017). The epistemic component of rationality (Habermas, 2014) can be observed in the discussion (Paolo: It's not true! We were at home two days!), but is not enhanced by the teacher. Consequently, children's discussion is evolving to a common agreement (Paolo: the $8^{\text {th }}$; Laura: No no no! It is the $7^{\text {th }}$ !). In the situation described the teacher doesn't ask to the child to better explain their thought, and children are not able to do this autonomously. As a consequence, children's communicative rationality is not enhanced.

The discussion among the children is not resolved, nor is any way out offered by the teacher. The discussion ends and the two children get stuck in their own opinion. Also, only two children took part in the discussion, a third tried to participate but failed to get involved due to not understanding, and the rest of the class did not take part in the exchange.

\subsection{Critical Dialogical Type of Exchange April}

A child comes with a candy-package for his birthday. Each child can have a candy. At the end, the teacher starts with a question.

Teacher. I have my candy-package. How can I understand how many candies were in the package this morning?

Matteo: You have to count.

Teacher. what do you mean? Can you explain?

Paolo: I think that Matteo means that you have to put on one side the candies that you have counted. On the other side the candies that you have not counted yet. So, you can understand how many candies you had.

Laura: Eeeeeeehhhhhh? 
Teacher. Maybe I have to explain better the question. If I want to know how many candies was in the package at the beginning, what can I do?

Matteo: Empty the bag!

Teacher. Ok. And now? What can I do?

Laura: Maybe ... you count? You can count us ... so we know how many candies we have eaten ... so ... how many candies were in the bag.

Paolo: No no no.

Matteo: I agree with Paolo. It's different. You can count the candies (the child counts four candies) that you have. If you do four plus 22 (the number of the children at school that day because three are at home) you can understand how many candies were in the package at the beginning.

Teacher. Does everyone agree?

Sara: Yes!

Teacher. Does someone else desire to say something different?

Elena: What happens tomorrow? Do we have enough candies?

Matteo: We are 22. So we can use three tomorrow and one will be still in the package.

Teacher. Can you explain better what you mean, so that everyone can understand?

Matteo: Because three are at home ... They will eat the candies tomorrow.

Also in this situation, the teacher starts with a question related to a situation at issue ("How can we understand how many candies we had in the package?"). Differently from the other two transcriptions presented before, here one child answers, but another one immediately tries to explain what the first child was saying. This shows that Paolo is trying to express his epistemic rationality, giving an answer trying to explain a motivation in the context (Habermas, 2014).

In this situation, the approach of the teacher is different, because she invites children to be critic, reflecting on the strategic choices used ("Does someone else desire to say something different?"). This helps the teacher in stimulating children's teleological rationality. The teacher, having been trained during the research project in enhancing children's rational behavior and dialogical critical thinking, invites children to explain their thought in a comprehensible way, trying to enrich their communicative rationality.

As a result, children reach a critical dialogical type of exchange, showing an explicit interdependence between interventions ("I think that Matteo means that you have to put on one side the candies that you have counted. On the other side the candies that you have not counted yet. So, you can understand how many candies you had.") in a situation in which a process of inquiry is established. Children shows spontaneous and complete justifications, with a critic approach ("No no no") that lead to a modification of the initial idea ("Paolo: It's different."; "Matteo: I agree with Paolo. It's different"; "Teacher. Does everyone agree? Sara: Yes!”).

This highlights that in a dialogical exchange in which children are able to ex- 
press the three components of Habermas' rationality, a dialogical type of exchange can be reached (Daniel \& Fiema, 2017).

\subsection{Critical Dialogical Type of Exchange: A Way for Resolving Conflict? April}

Below is a transcript of a dialogue that took place among children in the last days of observation.

(On the floor of the classroom there are wooden sticks, $30 \mathrm{~cm}$ long.)

Teacher. Can you build some geometric shapes? I would like you to work in pairs today.

(The children are divided into pairs. After a few minutes the teacher's attention is caught by a group of two girls who are talking animatedly. The teacher comes near the girl, listening and not interfering. The two girls seem too concentrated in the discussion for being able to notice the teacher).

Maria: it's wrong!

Anna: Why?

Maria: because we can't! a circle has no sides!

Anna: if we take a lot of sticks...

Maria: $A$ circle is a circle, sides are sides.

(Anna shakes her head.)

Maria: the sides of the circle are ... bent ...

(Anna notices the teacher)

Anna: Am I right?

Teacher. Can you explain your opinion Anna so that we can understand?

Anna: I like circles. I think that if we take lot of sticks ... we can build a circle ...

Teacher. Should we try?

(They build a shape like a circle)

Teacher. Anna, what do you think?

Anna: it seems a circle.

Maria: But is it a circle for you?

Anna (thinking) ... similar ...

Teacher. We could observe the problem from another point of view. What if ... we choose another object for building the shape?

Anna: Maria, what should we use?

Maria: something ... something ... that we can bend ...

Anna: without breaking it though ...

Maria: $A$.... rope?

Anna: I like it:

After many attempts in which the teacher tried to ask questions with focus about the importance of criticism and explanation as requested by the training related to this research project, children's attitudes have changed. In this examples Anna and Maria express their thought ("Maria: it s wrong!") and discuss trying to explain their opinion ("Maria: $A$ circle is a circle, sides are sides") 
in different way ("Maria: the sides of the circle are ... bent ...”). This implies that in this dialogue Anna and Maria show the components of rationality (Habermas, 2014). They are interested in other's opinion, but each one tries in the beginning just to show that they are right. Here the teacher shows her interest in stimulating children's reflection and dialogue, using questions related to communicative action, as open questions (“Teacher. Anna, what do you think?"), requesting of explanations or clarification ("Teacher. Can you explain your opinion Anna so that we can understand?"). Then the teacher appeals to the situation where disagreement between children arises as a source for discussion, leading children to listen each other with the aim of finding a common solution, better than the previous proposed by one child alone ("Teacher. We could observe the problem from another point of view. What if ... we choose another object for building the shape?") This helps Anna and Maria in finding an agreement. This shows that children have reached a dialogical type of exchange (Daniel \& Fiema, 2017). For reaching an agreement the intervention of the teacher is essential. An interesting aspect is that the teacher manages to resolve the conflict by guiding the children not only to express their opinion, but also to reason together to find the best solution to the problem.

\section{Conclusion}

Our findings show that dialogical thinking and rational behavior may be promoted already in early childhood. The analysis of the development of children exchange brings to the crucial role of the teacher, who is fundamental to support and encourage children's dialogical critical thinking and rational behavior. Results highlight that the teacher's approach is important not just in raising the level of dialogue up to a critical dialogical type of exchange, but also in helping children to express their thoughts, discuss with criticism and resolve the conflict trying to find a common solution. More specifically, the teacher may promote children's dialogical critical thinking and rational behavior:

- stimulating children's criticism: This means that teachers' role is to promote listening peers' ideas, but also to criticize them, being this approach an important and necessary tool to reach a common goal;

- asking specific questions that could enhance the three component of Habermas' rationality (such as inviting children to justify their opinions, challenging children by asking them to reason about a topic and to make sense of their ideas, inviting children to reflect on the strategic choices that they used, inviting children to explain their thought in a comprehensible way).

Results show also that children can reach a critical dialogical type of exchange, expressing the three components (epistemic, teleological, communicative) of Habermas' rationality. However, this does not mean that all children are involved in the discussion. As can be seen from the transcripts, only some children take part in the discussion. The discussion is always among a small group of children, and the others observe or take part in the situation but not really to the dialogue. Three children have never been involved. An important question to 
ask therefore is what the role of the teacher should be. In those examples, the focus of the teacher is to enhance rational behavior and dialogical critical thinking of children who decide to participate in the dialogue. The desirable result should be able to rise these competences in all children who participate in the activity. Although the study is conducted in a specific and limited context, it helps in rising questions that are relevant about argumentation in ECEC institutions and teacher's role. But some information cannot be deduced clearly from this set of data. For example, it is not clear if the prevalence of certain dimensions can depend on the type of question posed by the teacher. Further and more extended studies could be performed in order to understand the relationship between rational behavior and dialogical critical thinking in pre-school children.

\section{Acknowledgements}

We would like to thank Genova Municipality and teachers related to Laboratorio zero, under the guidance of Dr. Alda Motta.

\section{Conflicts of Interest}

The authors declare no conflicts of interest regarding the publication of this paper.

\section{References}

Boero, P. (2011). Argumentation and Proof: Discussing a "Successful" Classroom Discussion. In M. Pytlak, T. Rowland, \& E. Swoboda (Eds.), Proceedings of the Seventh Congress of the European Society for Research in Mathematics Education (pp. 120-130). Rzeszów: ERME.

Boero, P., \& Planas, N. (2014). Habermas' Construct of Rational Behavior in Mathematics Education: New Advances and Research Questions. In P. Liljedahl, C. Nicol, S. Oesterle, \& D. Allan (Eds.), Proceedings of the Joint Meeting of PME 38 and PME-NA 36 (Vol. 1, pp. 205-235). Vancouver: PME.

Boero, P., Douek, N., Morselli, F., \& Pedemonte, B. (2010). Argumentation and Proof: A Contribution to Theoretical Perspectives and Their Classroom Implementation. The Proceedings of PME 34 the 34th Conference of the International Group for the Psychology of Mathematics Education, Universidade Federal de Minas Gerais, 179-209.

Bondioli, A. (1996). Gioco e educazione. FrancoAngeli.

Conner, A. (2017). An Application of Habermas' Rationality to the Teacher's Actions: Analysis of Argumentation in Two Classrooms. CERME 10, Dublin, February 2017, ffhal-01873068f.

Daniel, M.-F., \& Fiema, G. (2017). Dialogical Critical Thinking in Children. Knowledge Cultures, 5, 42-65. https://doi.org/10.22381/KC5420174

Daniel, M.-F., \& Gagnon, M. (2011). Developmental Process of Dialogical Critical Thinking in Groups of Pupils Aged 4 to 12 Years. Creative Education, 2, 418. https://doi.org/10.4236/ce.2011.25061

Golding, C. (2011). Educating for Critical Thinking: Thought-Encouraging Questions in a Community of Inquiry. Higher Education Research \& Development, 30, 357-370. https://doi.org/10.1080/07294360.2010.499144

Habermas, J. (2014). Truth and Justification. Hoboken, NJ: John Wiley \& Sons. 
Hundeland, P. S., Carlsen, M., \& Erfjord, I. (2020). Qualities of Mathematical Discourses in Kindergartens. ZDM: Mathematics Education, 52, 691-702. https://doi.org/10.1007/s11858-020-01146-w

Jenkins, D. M., \& Cutchens, A. B. (2011). Leading Critically: A Grounded Theory of Applied Critical Thinking in Leadership Studies. Journal of Leadership Education, 10, 1-21. https://doi.org/10.12806/V10/I2/TF1

Krummheuer, G. (1995). The Ethnography of Argumentation. In P. Cobb, \& H. Bauersfeld (Eds.), The Emergence of Mathematical Meaning: Interaction in Classroom Cultures (pp. 229-269). Hillsdale, NJ: Lawrence Erlbaum Associates.

Levenson, E., \& Morselli, F. (2018). Un progetto a lungo termine per lo sviluppo delle competenze argomentative. Conferenze e Seminari, Bergamo, 47-60.

Lipman, M. (2003). Thinking in Education. Cambridge: Cambridge University Press. https://doi.org/10.1017/CBO9780511840272

Ministero della Pubblica Istruzione (2012). Indicazioni nazionali per il curricolo della scuola dell'infanzia e del primo ciclo d'istruzione. Roma: MPI.

Morselli, F., \& Boero, P. (2009). Habermas' Construct of Rational Behaviour as a Comprehensive Frame for Research on the Teaching and Learning of Proof. In F. L. Lin et al. (Eds.), Proceedings of the ICMI Study 19 Conference: Proof and Proving in Mathematics Education (Vol. 2, pp. 100-105). Taipei: Normal University.

Quintana, R., \& Correnti, R. (2019). The Right to Argue: Teaching and Assessing Everyday Argumentation Skills. Journal of Further and Higher Education, 43, 1133-1151. https://doi.org/10.1080/0309877X.2018.1450967

Robotti, E., Morselli, F., Granone, F., \& Pollarolo, E. (2020). Outdoor Mathematics Education: Analisi di un caso di studio sviluppato nella scuola dell'infanzia norvegese e italiana. In Scenari di futuro: Creatività e immaginazione per lo sviluppo sostenibile (pp. 69-84). Bergamo: Zeroseiup.

Siraj, I., Kingston, D., \& Melhuish, E. C. (2015). Assessing Quality in Early Childhood Education and Care. Sustained Shared Thinking and Emotional Well-Being (SSTEW) Scale for 2-5-Year-Olds Provision. London: Trentham Books.

Zhuang, Y., \& Conner, A. (2018). Analysis of Teachers' Questioning in Supporting Mathematical Argumentation by Integrating Habermas' Rationality and Toulmin's Model. 40th Annual Meeting of the North American Chapter of the International Group for the Psychology of Mathematics Education, Greenville, 15-18 November 2018, 1323-1330. 